\title{
ELEKTROKOAGULASI MONOPOLAR UNTUK MENYISIHKAN ORGANIK DAN MINYAK LEMAK AIR BUANGAN DOMESTIK (GREY WATER)
}

\section{TREATMENT OF DOMESTIC WASTEWATER (GREY WATER) BY ELECTROCOAGULATION USING ALUMINUM ELECTRODES}

\author{
Ansiha Nur ${ }^{1}$ dan Agus Jatnika ${ }^{2}$ \\ Teknik Lingkungan Fakultas Teknik Universitas Andalas \\ E-mail: ${ }^{1}$ ansiha@ft.unand.ac.id, ${ }^{2}$ agusje@tl.itb.ac.id
}

\begin{abstract}
ABSTRAK
Elektrokoagulasi merupakan teknologi elektrokimia untuk mengolah limbah organik dan anorganik tanpa menggunakan bahan kimia sehingga tidak menambah beban pencemaran lingkungan. Kinerja elektrokoagulasi dipengaruhi oleh jenis elektroda, kerapatan arus dan jumlah elektroda. Tujuan penelitian ini untuk mengetahui efektifitas penurunan organik (COD) dan minyak lemak dari air buangan domestik (grey water) melalui proses elektrokoagulasi. Percobaan dilakukan secara batch menggunakan konfigurasi susunan elektroda monopolar, dengan jenis elektroda berupa plat alumunium 95,7\%. Variasi penelitian pada reaktor batch adalah terhadap kerapatan arus listrik 21-104 A/ $\mathrm{m}^{2}$, waktu detensi dan pH. Kondisi optimum diperoleh pada kerapatan arus $104 \mathrm{~A} / \mathrm{m}^{2}$ pada menit ke-15 dengan penyisihan COD dan minyak lemak yaitu sebesar 87,48\% dan 77,50\%. Hasil proses elektrokoagulasi ini menunjukkan nilai COD sebesar 15,02 mg/L dan minyak lemak 4,20 mg/L berada di bawah baku mutu Keputusan Menteri Negara Lingkungan Hidup Nomor 112 Tahun 2011 kelas 3, untuk dimanfaatkan untuk penyiraman tanaman dan penggelontoran toilet hotel.
\end{abstract}

Kata kunci: elektrokoagulasi, elektroda aluminium, monopolar, kerapatan arus, grey water

\section{ABSTRACT}

Electrocoagulation is an electrochemical technology to treat organic and inorganic wastewater without the use of chemicals so as not to increase the burden of environmental pollution. Electrocoagulation performance is influenced by electrode type, current density and number of electrodes. The purpose of this research is to know the effectiveness of COD and oil grease removal from domestic waste water (grey water) through electrocoagulation process. The experiment was conducted in batch using monopolar electrode configuration, with aluminum electrodes 95,7\%. In this research, electric current density 21-104 A/ $\mathrm{m}^{2}$, detention time and $\mathrm{pH}$ were varied. The optimum condition was obtained at current density of $104 \mathrm{~A} / \mathrm{m}^{2}$ for 15 minutes with COD and oil grease removal consecutively are $87.48 \%$ and $77.50 \%$. The result of this electrocoagulation process shows COD and oil grease concentration of $15.02 \mathrm{mg} / \mathrm{L}$ and $4.20 \mathrm{mg} / \mathrm{L}$ are under the standard of Ministry of Environment Decree No. 112 Year 2011 grade 3, to be used for watering plants and flushing the hotel toilet.

Keywords: electrocoagulation, aluminum electrode, monopolar, current density, grey water

\section{PENDAHULUAN}

Grey water merupakan bagian dari limbah cair domestik yang proses pengalirannya tidak melalui toilet, seperti air bekas mandi, air bekas mencuci pakaian, dan air bekas cucian dapur. Sekitar $60-85 \%$ dari total volume kebutuhan air bersih akan menjadi limbah cair domestik (Metcalf, 2004). Potensi kuantitas grey water yang besar ini dapat didayagunakan untuk dimanfaatkan kembali jika dikelola dengan baik. Grey water dapat digunakan sebagai sumber air untuk keperluan penyiraman tanaman atau untuk penggelontoran toilet, terutama untuk hotel atau apartemen yang membutuhkan air bersih dalam jumlah besar. Grey water dapat digunakan sebagai sumber air untuk keperluan penyiraman tanaman karena grey water mengandung fosfat, potasium, dan nitrogen yang merupakan sumber nutrisi yang baik bagi tumbuhan, dan grey water juga mengandung bakteri patogen yang lebih sedikit dibandingkan dengan black water dan greywater terdekomposisi lebih cepat 
daripada black water (Gulyas, 2007). Hal tersebut membuat grey water lebih mudah untuk dimanfaatkan kembali dibandingkan dengan black water yang harus melewati proses pengolahan terlebih dahulu sebelum dimanfaatkan kembali

Hotel Grand Royal Panghegar berlokasi di Jalan Merdeka No.2, Bandung terdiri dari 21 lantai dengan luas total $65.000 \mathrm{~m}^{2}$. Rata-rata kebutuhan air bersih untuk operasional Hotel bintang 4 sebesar $750 \mathrm{~m}^{3} /$ hari (Dinas Pariwisata Daerah Provinsi Jawa Barat, 2014) dan akan menghasilkan air buangan domestik 60-85\% dari pemakaian air bersih.

Untuk dapat dimanfaatkan kembali, greywater harus diolah terlebih dahulu melalui suatu teknologi pengolahan air buangan agar memenuhi persyaratan. Pemanfaatan kembali grey water ini sekaligus mengurangi dampak negatif terhadap lingkungan, seperti peningkatan beban pencemaran pada badan air.

Beberapa teknologi pengolahan air limbah yang telah diterapkan umumnya berupa penambahan bahan kimia, sedimentasi, netralisasi, lumpur aktif dan anaerobik. Penggunaan bahan kimia selektif pada pengolahan limbah cair fase air biasanya hanya mampu mengatasi persoalan limbah dengan karakteristik tertentu, sehingga effluen yang dihasilkan dari proses pengolahan kimia biasanya masih mengandung zat padat terlarut sehingga belum dapat dibuang ke lingkungan (Chen,G., 2004).

Salah satu teknologi yang dikembangkan pada pengolahan grey water adalah elektrokoagulasi (Lin et al., 2005, Jamrah et.al, 2007, Yan et al., 2008, Li et al., 2009 dan Rodrigo, 2010). Elektrokoagulasi juga dapat digunakan dalam proses pengolahan limbah, seperti limbah tekstil, limbah minyak bumi, rumah tangga, tar sand \& oil shale, limbah chemical fiber, oil-water emulsion, oily wastewater clay suspension, nitrit, sisa zat warna serta dapat mengurangi mikroorganisme dalam air (Mollah et al, 2001, Holt et al., 2004, Moussavi et al., 2011 dan Butler et al., 2011).

Elektrokoagulasi mempunyai efisiensi yang tinggi dalam penghilangan kontaminan, menghasilkan effluen yang jernih, tidak berwarna dan tidak berbau, waktu operasional yang pendek, lumpur yang dihasilkan lebih sedikit, stabil dan mudah disisihkan (Notodarmojo, 1996, Mollah et al., 2004, Lin et al., 2005, Holt et al., 2005, Rodrigo et al., 2010, Butler et al.,2011, Hariph et al.,2012 dan Mechelhoff et al., 2013). Untuk mendapatkan kebutuhan pelepasan ion logam yang besar pada pengolahan air limbah, maka prsoses elektrokoagulasi menggunakan susunan elektroda monopolar yang disusun secara paralel (Mollah et al., 2004).

Penelitian ini mempelajari proses elektrokoagulasi menggunakan konfigurasi pasangan elektroda aluminium susunan monopolar untuk menurunkan COD dan minyak lemak pada grey water hotel sehingga dapat dimanfaatkan kembali untuk penyiraman tanaman dan penggelontoran toilet.

\section{METODOLOGI PENELITIAN}

Pengambilan sampel air buangan (grey water) berasal dari bak ekualisasi Instalasi Pengolahan Air Buangan (IPAL) hotel Grand Royal Panghegar yang berlokasi di Jalan Merdeka No.2 di Kota Bandung. Penelitian dilakukan di Laboratorium Kualitas Air Teknik Lingkungan ITB.

Reaktor elektrokoagulasi sistem batch menggunakan beaker glass 2 liter (Gambar 1). Elektroda dari plat alumunium ( $\mathrm{Al}$ ) 95,7 $\%$ (Laboratorium Teknologi Mineral dan Batu Bara, 2014) dengan ukuran $8 \times 20 \mathrm{~cm}$ sebanyak 4 buah (2 buah anoda dan 2 buah katoda). Plat elektroda terendam $15 \mathrm{~cm}$ dalam larutan. Elektroda berupa katoda dan anoda ini berperan sebagai penghantar arus listrik searah dan larutan limbah sebagai elektrolit.

Susunan konfigurasi elektroda monoolar disusun secara paralel (Mollah et al.,2004), dipasang secara berselang antara anoda dan katoda dengan jarak $2,5 \mathrm{~cm}$. Semua elektroda dihubungkan dengan arus listrik yang berasal dari sumber arus DC (Diamond GSV 3000, 0$20 \mathrm{~V}$ dan 0-34 A), yaitu dua elektroda dihubungkan dengan kutub positif dan dua elektroda dengan kutub negatif. Reaktor dilengkapi dengan magnetic stirrer yang diatur pada skala 5 agar koagulan menjadi homogen dan tersebar merata di dalam larutan. 


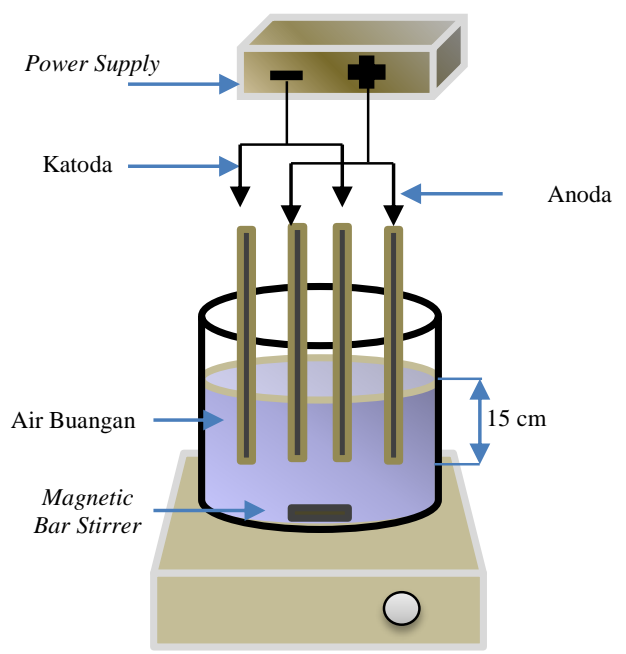

Gambar 1. Rangkaian reaktor elektrokoagulasi

cairan pada reaktor. Setělah itu elektroda dipasang ke dalam reaktor dengan menyambungkan kabel kepada setiap elektroda. Arus listrik yang digunakan berasal dari listrik AC yang dirubah menjadi arus DC menggunakan DC power supply sehingga memudahkan dalam mengatur tegangan yang akan melewati rangkaian

Variasi kuat arus yang digunakan pada peneltian ini adalah 0,5-2,5 A setara dengan kerapatan arus (current density) 21-104 A/m ${ }^{2}$, waktu detensi 2-60 menit dan $\mathrm{pH} 2-12$. Metode uji yang digunakan pada penelitian ini adalah grab sample yaitu sampel diambil langsung pada saat tertentu dari satu kedalaman yang sama pada reaktor batch Percobaan pengukuran dilakukan secara triplo. Efisiensi penyisihan dihitung menggunakan persamaan 1.

$\% \mathrm{R}=\frac{\mathrm{C}_{\text {in }}-\mathrm{C}_{\text {out }}}{\mathrm{C}_{\text {in }}} \times 100 \%$

\section{Dimana:}

$\mathrm{R}$ : Penyisihan

$\mathrm{C}_{\text {in }}$ : Konsentrasi pada larutan saat awal (mg/L)

$\mathrm{C}_{\text {out }}$ : Konsentrasi pada larutan saat kesetimbangan $(\mathrm{mg} / \mathrm{L})$

Pengamatan ukuran flok yang terbentuk hasil proses elektrokoagulasi menggunakan mikroskop cahaya Olympus CX-21, diamati dengan menggunakan lensa okuler. Flok diambil dengan menggunakan pipet tetes dan diletakkan secara hati-hati di atas kaca preparat dan selanjutnya diamati dengan mikroskop cahaya. Pengamatan terhadap kecepatan pengendapan menggunakan standard method 2710 dengan mengamati interface permukaan flok dengan air pada waktu tertentu dengan menggunakan gelas ukur 1 liter dengan tinggi 29,7 cm. Pengukuran waktu menggunakan stopwatch.

\section{HASIL DAN PEMBAHASAN}

\section{Penyisihan COD dan Minyak Lemak}

Penyisihan COD terbesar terjadi pada kerapatan arus $104 \mathrm{~A} / \mathrm{m}^{2}$ pada waktu 15 menit sebesar $87,48 \%$. Pada kerapatan arus ini, ion $\mathrm{Al}^{3+}$ teroksidasi dalam jumlah banyak dan berikatan dengan kuat dengan $\mathrm{OH}^{-}$dan terdestabilisasi membentuk flok dengan cepat pada menit ke-15. Mekanisme penyisihan COD disebabkan zat-zat organik yang terlarut ikut terikat dengan flok dan teroksidasi akibat kehadiran oksidator kuat, yaitu $\mathrm{O}_{2}$.

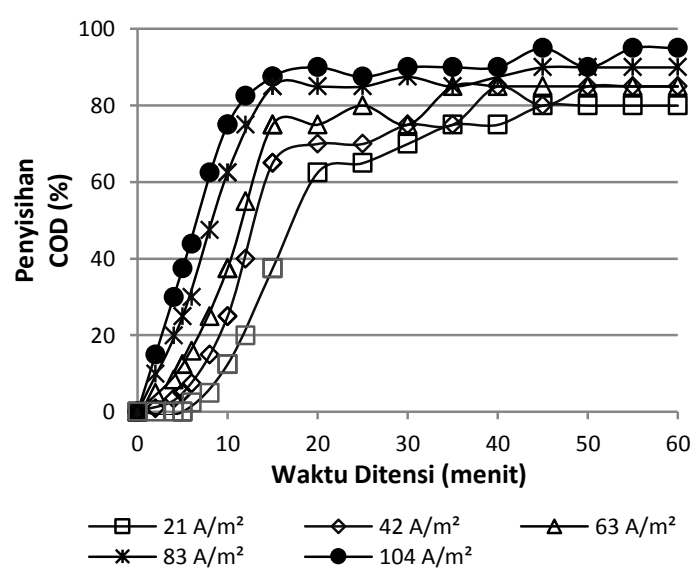

Gambar 2. Efisiensi Penyisihan COD

Penyisihan terbesar minyak dan lemak (Gambar 3) terjadi pada kerapatan arus 104 $\mathrm{A} / \mathrm{m}^{2}$ pada waktu 15 menit sebesar $77,50 \%$. Menurut Reynolds (1982), koloid jenis minyak dan lemak ini tergolong koloid hidrofolik yang memiliki muatan negatif. Jumlah $\mathrm{Al}^{3+}$ yang dilepaskan ke dalam larutan sangat mempengaruhi interaksi yang terjadi pada mekanisme destabilisasi minyak dan lemak. Pada penambahan pelepasan $\mathrm{Al}^{3+}$, pemerangkapan dan pengikatan minyak dan lemak semakin tinggi oleh inti koagulan sehingga penyisihan juga semakin besar. 


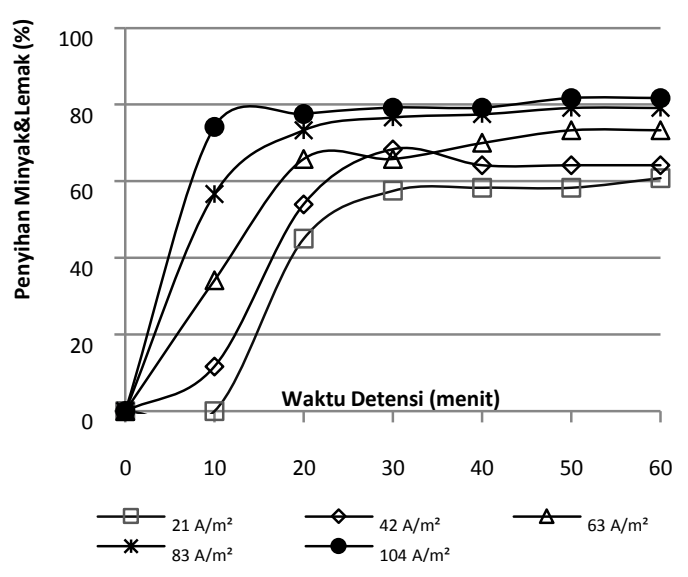

Gambar 3. Efisiensi Penyisihan Minyak \& Lemak

Secara keseluruhan, penyisihan COD dan minyak lemak pada grey water hotel ini mengalami penurunan sampai pada menit ke15 , lalu relatif konstan dan bahkan mencapai kondisi steady state sampai menit ke-60. Mekanisme penyisihan selama proses elektrokoagulasi melalui reaksi berikut ini (Mollah et al., 2004).

Anoda: $\mathrm{Al} \rightarrow \mathrm{Al}^{3+}+3 \mathrm{e}^{-}$

Katoda: $2 \mathrm{H}_{2} 2 \mathrm{O}_{(\mathrm{l})}+2 \mathrm{e}^{-} \rightarrow \mathrm{H}_{2(\mathrm{~g})}+2 \mathrm{OH}$

Dalam Larutan:

$\mathrm{Al}^{3+}{ }_{(\mathrm{aq})}+3 \mathrm{H}_{2} \mathrm{O}(\mathrm{l}) \rightarrow \mathrm{Al}(\mathrm{OH})_{3(\mathrm{~s})}+3 \mathrm{H}^{+}$

\section{Pengaruh Variasi pH}

Penyisihan paling baik terjadi pada $\mathrm{pH}$ 6-8. Menurut Harif et al (2012), pada rentang tersebut terjadi proses hidrolisis ion $\mathrm{Al}$ yang menghasilkan senyawa $\mathrm{Al}(\mathrm{OH})^{2+}, \mathrm{Al}_{2}(\mathrm{OH})^{24+}$, $\mathrm{Al}(\mathrm{OH})^{3+}$ dan senyawa polimer $\mathrm{Al}_{13}(\mathrm{OH})_{32}{ }^{7+}$ yang efektif dalam proses koagulasi. Pada $\mathrm{pH}$ di bawah 4 senyawa yang terbentuk adalah ion $\mathrm{Al}^{3+}$, sedangkan pada $\mathrm{pH}$ di atas 10 senyawa yang terbentuk adalah $\mathrm{Al}(\mathrm{OH})^{4-}$. Kedua senyawa ini bersifat amfoter dan memiliki sifat kurang efektif dalam proses koagulasi.

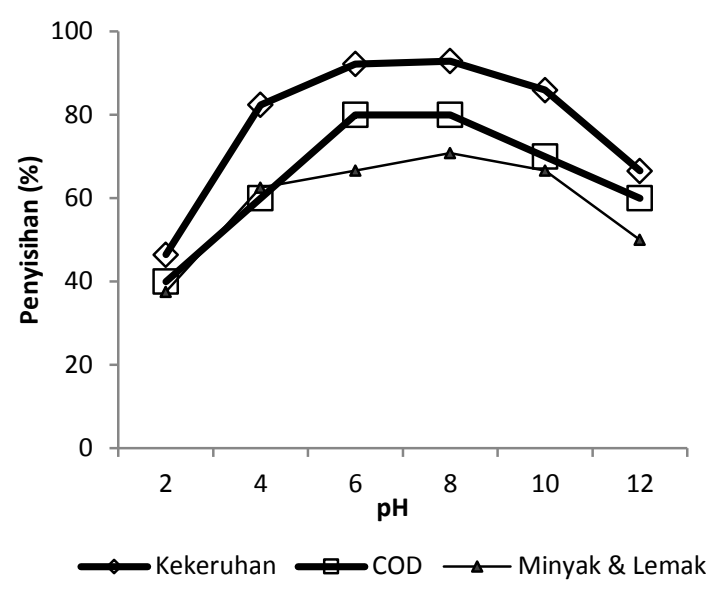

Gambar 4. Penyisihan pada variasi $\mathrm{pH}$

\section{Pembentukan Flok}

Flok langsung terbentuk sesaat arus listrik pada reaktor dimatikan, kemudian dengan segera pada menit berikutnya terjadi proses pemisahan flok dari supernatannya, hingga pada menit ke-15 (Gambar 5) terjadi pemisahan flok dan supernatannya dengan sempurna. Hal ini menunjukkan bahwa dengan pemakaian arus listrik pada kerapatan arus $104 \mathrm{~A} / \mathrm{m}^{2}$ menyebabkan proses koagulasi - flokulasi lebih mudah terjadi dan berlangsung cepat serta menghasilkan supernatan yang jernih dan tidak berwarna.

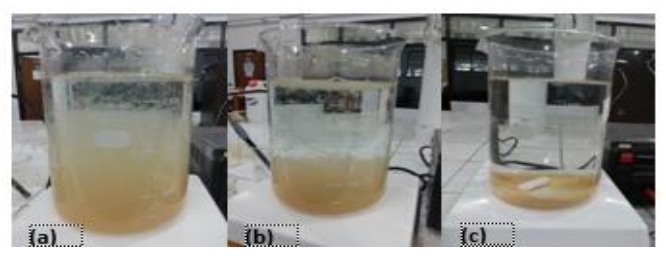

Gambar 5. Proses Pemisahan Flok dari

Supernatan Setelah Running 15 Menit pada $104 \mathrm{~A} / \mathrm{m}^{2}$

Pada penelitian ini diukur kecepatan pemisahan flok dan supernatan pada kondisi optimum yaitu pada kerapatan arus $104 \mathrm{~A} / \mathrm{m}^{2}$ pada interval waktu 60 menit. Kecepatan pengendapan flok adalah 0,0571 - 0,125 cm/detik (Gambar 6). 


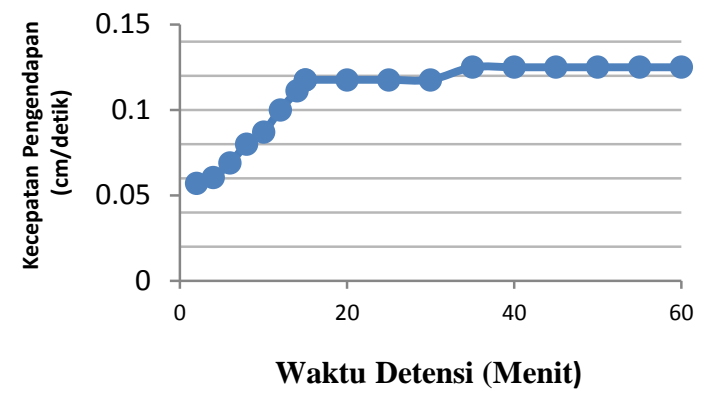

Gambar 6. Kecepatan Pengendapan Flok pada Kerapatan Arus $104 \mathrm{~A} / \mathrm{m}^{2}$

Tabel 1. Ukuran flok

\begin{tabular}{cc}
\hline $\begin{array}{c}\text { Waktu Detensi } \\
(\text { menit })\end{array}$ & $\begin{array}{c}\text { Ukuran Flok } \\
(\boldsymbol{\mu m})\end{array}$ \\
\hline 2 & $1-120$ \\
4 & $3-60$ \\
6 & $50-100$ \\
8 & $90-150$ \\
10 & $150-250$ \\
15 & $250-1000$ \\
\hline
\end{tabular}

Pengamatan flok yang terbentuk menggunakan mikroskop cahaya Olympus CX-21. Pada Gambar 7 dapat dilihat bahwa partikel tersuspensi dalam air memilki ukuran yang sangat kecil, antara 0,001 mikron $\left(10^{-6}\right.$ $\mathrm{mm})$ sampai 1 mikron $\left(10^{-3} \mathrm{~mm}\right)$ pada 0 menit dan kemudian terdestabilisasi membentuk flok makin lama makin besar seiring penambahan rapat arus (Tabel 1).

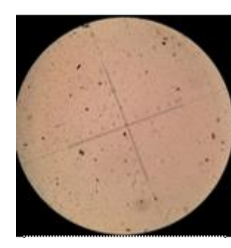

(a) 0 menit

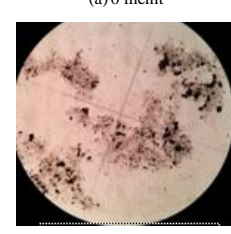

(d) 6 menit

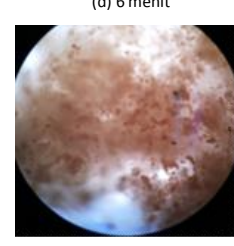

(g) 12 menit

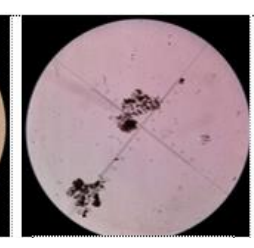

(b) 2 menit

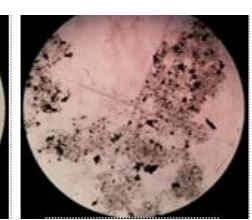

(e) 8 menit

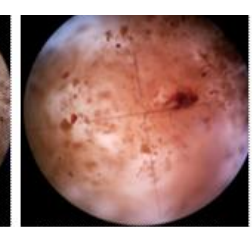

(h) 15 menit

Gambar 7. Bentuk dan ukuran flok

Pada metode elektrokoagulasi, ion $\mathrm{Al}^{3+}$ yang digunakan sebagai koagulan bersifat lebih murni dikarenakan berasal dari logam yang memiliki kemurnian tinggi bila dibandingkan dengan bahan kimia. Selain itu lumpur yang dihasilkan melalui proses sedimentasi (pengendapan) lebih sedikit karena flok pada proses elektrokoagulasi sebagian mengalami flotasi (pengapungan). Hal ini telah dibuktikan juga berdasarkan pengamatan dan pengukuran flok yang dilakukan oleh Harif (2012) dengan membandingkan flok yang terbentuk dari proses elektrokoagulasi menggunakan elektroda aluminium dan penambahan bahan kimia berupa koagulan komersial $\left(\mathrm{Al}_{2}(\mathrm{SO})_{4} 18 \mathrm{H}_{2} \mathrm{O}\right)$, dimana flok yang terbentuk pada waktu 6 menit memiliki ukuran $215 \mu \mathrm{m}$ pada $0,22 \mathrm{~A}$ dan $65 \mu \mathrm{m}$ pada $30 \mathrm{mg} / \mathrm{l}$ alum. Sementara hasil penelitian yang dilakukan oleh Mariam (2012) dengan penambahan koagulan tawas konvensional kepada air baku diperoleh ukuran flok $0-0,5$ $\mathrm{mm}$.

\section{SIMPULAN}

Berdasarkan hasil penelitian dapat disimpulkan variasi kerapatan arus $104 \mathrm{~A} / \mathrm{m}^{2}$ dan $\mathrm{pH} \quad 6-8$ selama 15 menit dapat menyisihkan COD dan minyak lemak grey water hotel masing-masing $87,48 \%$ dan $77,50 \%$. Flok yang terbentuk memiliki diameter 250 - $1000 \mu \mathrm{m}$. Hasil proses elektrokoagulasi menggunakan konfigurasi elektroda aluminium susunan monopolar pada proses elektrokoagulasi ini mampu menurunkan organik dan minyak lemak dalam air buangan domestik (grey water) hotel, dan berada di bawah baku mutu Keputusan Menteri Negara Lingkungan Hidup Nomor 112 Tahun 2011.

\section{DAFTAR PUSTAKA}

Bhani-Melhem, K., Smith, E. 2012. Grey water Treatment By A Continuous Process Of An Electrocoagulation Unit And A Submerged Membrane Bioreactor System. Journal of Chemical Engineering, Vol. 198-199, pp. 201210.

Butler, et al. 2011. Electrocoagulation in Wastewater. Journal of Wastewater Treatment. Water., Vol. 3, pp.495-525

Faiqun, Ni'am, Moh. 2007. Removal of COD and Turbidity to Improve Waste Water Quality Using Electrocoagulation Technique. Journal of Analytical Sciences. Vol. 11 No : 1, 2007 P : 198205. 
Gulsun, M. and Hosten, C. 2010. A comparative study of electrocoagulation and coagulation of aqueous suspensions of kaolinite powders. Journal of Hazardous Materials., Vol. 176, pp. 735-740.

Gulyas, Holger. 2007. Greywater Reuse: Concepts, Benefits, Risks and Treatment Technologies. International Conference on Sustainable Sanitation.

Hammer. J. Mark. 2008. Water and Wastewater Technology. Pearson Education International. New Jersey.

Harif, T., Khai, M., dan Adin, A. 2012. Electrocoagulation Versus Chemical Coagulation: Coagulation/Flocculation Mechanisms and Resulting Floc Characteristics. Water Research 46, $3177-3188$.

Holt, P. K., Barton, G. W., dan Mitchell, C. A. 2005. The Future for Electrocoagulation as A Localised Water Treatment Technology. Chemosphere. 59: 355367.

Idaman, Nusa. 2013. Minimasi Air Limbah dan Teknologi Daur Ulang Limbah. Pelatihan Pengeloaan air limbah BPLHD DKI Jakarta. 18 Juni 2013. Pusat Lingkungan (PTL) - BPPT

Jamrah, A., Al-Futaisi, A., Prathapar, S., AlHarrasi, A. 2007. Evaluating Grey water Reuse Potential for Sustainable Water Resources Management in Oman. Environmental Monitoring Assessment (2008) 137:315-327.

Khemis, M., 2005. Electrocoagulation for the treatment of oil suspensions relation between the rates of electrode reactions and the efficiency of waste removal. Process Saf.Environ.Prot.83(B1),50-57

Li, Fangyue et al. 2009. Review of The Technological Approaches for Grey water Treatment and Reuses. Science of the Total Environment Vol.407, pp.3439-3449.

Lin, C., Lo.,S., Kuo, C dan Wu, C. 2005. PilotScale Electrocoagulation with Bipolar
Aluminum for On-Site Domestic

Greywater Reuse. Journal of Environmental Engineering, pp 491495.

M.Khemis, J.-P. Leclerc, G. Tanguy, G. Valentin, F. Lapicque F.,. 2006. Treatment of Industrial Liquid Wastes by Electrocoagulation: Experimental Investigations and an Overall Interpretation Model. Chem. Eng. Sci. 61, pp.3602-3609

Mechelhoff, et al. 2013. Electrochemical Behaviour of Aluminium In Electrocoagulation Processes. Chemical Engineering Science, Vol.95,pp. 301312 .

Metcalf and Eddy. 2004. Wastewater Engineering Treatment and Reuse. Mc Graw Hill Company. New York

Mollah, M.Y.A., Morkovsky, P., Gomes, J.A.G., Kesmez, M., Parga, J. and Cocke, D.L. 2004. Fundamentals, present and future perspectives of electrocoagulation. Journal of Hazardous Materials. Vol. B114, pp. $199-210$.

Mouedhen, G., Petris M.W., H.F. Ayedi. 2008. Behaviour of aluminum electrodes in electrooagulation process. Journal of Hazardous Materials, Vol. 150, pp. $124-135$.

Notodarmojo, S. 1996. Field and Pilot Scale Study on The Treatment Of Textile Industry by Using Electrocoagulation Processes in a Textile Factory Near Bandung. Research Dept. of Education

Rodrigo, M.A., Cañizares, P., Buitrón, C., Sáez, C. 2010. Electrochemical technologies for the regeneration of urban wastewaters. Electrochim. Acta.55: 8160-8164

Yang, Y., Liu, L., Jin, Q. 2008. Study on treatment of municipal domestic sewage by electrocoagulation and electroflotation. Journal Xi'an Univ. Architect. Tech. 